\title{
Proses Komunikasi Melalui Kegiatan Event Adopt Don't Shop Guna Mengkampanyekan Kesadaran Masyarakat agar Menyayangi Binatang
}

\author{
Vina Vinessa, Suherman Kusniadji \\ vina.vinessa@ymail.com, hermankusniadji@gmail.com \\ Fakultas Ilmu Komunikasi Universitas Tarumanagara
}

\begin{abstract}
This study title is Communication Process Through Adopt Don't Shop Event Activities to Campaign Public Awareness to Love Animals (Case Study at Indonesia Animal Defenders Foundation). The purpose of the study is to find out how the communication process is through the Adopt Don't Shop Event in order to raise people awareness to love animals. This study uses descriptive method with a qualitative approach. This study is using semistructured interviews and observations of three informants related to this study. The study data is gathered from interviews, observation,documentation and literature. This study is intended to fing out the communication process that occurs in Adopt Don't Shop event activities. Theories used in this study are communication process from Laswell, Stewart L. Tubbs and Sylvia Moss, Kotler (Kurniawati), John Vivian, Harold Laswell, Collin and Ivanovic, Goldblatt, Muyasaroh, Ardianto, and Yaverbaum namely public communication, social communication, mass communication, communication process, exhibition events, management event, communications campaign, new media, special event. The conclusion of this study is event activities are effective media to raise people awareness to love animals because of the good communication process and good events.
\end{abstract}

Keywords: Communication Process, Public Awareness, Event Activities.

\begin{abstract}
Abstrak
Penelitian ini berjudul Proses Komunikasi Melalui Kegiatan Event Adopt Don't Shop Guna Mengkampanyekan Kesadaran Masyarakat Agar Meyayangi Binatang (Studi Kasus Pada Yayasan Animal Defenders Indonesia). Tujuan penelitian adalah untuk mengetahui bagaimana proses komunikasi melalui kegiatan event Adopt Don't Shop guna menyadarkan masyarakat agar menyayangi binatang. Penelitian ini menggunakan metode deskriptif dengan pendekatan kualitatif. Penelitian akan menggunakan wawancara semi terstruktur dan observasi terhadap tiga informan yang berhubungan dengan penelitian ini. Data penelitian yang diperoleh bersumber dari wawancara, observasi, dokumentasi dan studi pustaka. Penelitian ini dimaksudkan untuk mengetahui proses komunikasi yang terjadi dalam kegiatan event adopt don't shop. Teori yang digunakan dalam penelitian adalah proses komunikasi dari Laswell. Stewart L.Tubbs dan Sylvia Moss, Kotler (Kurniawati), John Vivian, Harold Laswell, Collin dan Ivanovic, Goldblatt, Muyasaroh, Ardianto, dan Yaverbaum yakni komunikasi public, komunikasi social, komunikasi massa, proses komunikasi, event pameran, event manajemen, kampanye komunikasi, new media, special event. Kesimpulan dari penelitian ini adalah kegiatan event merupakan media yang efektif yang dapat menyadarkan masyarakat untuk menyayangi binatang karena adanya proses komunikasi dan event yang baik.
\end{abstract}

Kata Kunci: Proses Komunikasi, Kesadaran Masyarakat, Kegiatan Event. 


\section{Pendahuluan}

Sekarang ini hewan anjing atau kucing merupakan binatang yang paling banyak dipelihara masyarakat. Kedua hewan tersebut banyak dipelihara masyarakat karena tingkat kecerdasannya, dapat diajari, mempunyai perasaan yang lembut dan mudah untuk dirawat. Tidak hanya itu, banyak masyarakat Indonesia memelihara anjing maupun kucing sebagai teman bermain hingga menjaga rumah. Namun masih banyak masyarakat Indonesia yang belum mempunyai komitmen serta kesadaran untuk merawat dan menjaga sehingga banyak masyarakat yang tidak bertanggung jawab dan menelantarkan hewan peliharaan mereka. Hal tersebut tidak hanya merugikan hewan tersebut melainkan juga kepada masyarakat itu sendiri karena tanpa disadari saat kita menelantarkan hewan peliharaan, hewan tersebut dapat berkembang biak secara luas dan penyakit rabies. Rabies merupakan salah satu penyakit berbahaya yang tidak dapat disembuhkan karena langsung menyerang system syaraf otak, namun dapat dicegah melalui vaksinasi dan pembersihan luka yang baik. Banyak juga masyarakat yang tega menyiksa hewan tersebut demi kepuasaan pribadi, membunuh dengan tidak sewajarnya hingga dagingnya dijadikan makanan.

Hal ini yang membuat sekelompok masyarakat tergerak hatinya untuk membuat atau membangun sebuah organisasi yang berfokus pada hewan yang terlantar dan memberi hewan tersebut kehidupan yang layak seperti makanan dan tempat tinggal. Organisasi tersebut yang menampung hewan terlantar dan menggunakan beberapa event yang nantinya hewan tersebut akan diadopsi oleh masyarakat yang benar-benar berkomitmen untuk menjaga dan menyayangi hewan tersebut. Tujuan utama organiasi ini dibentuk adalah untuk memberi kesadaran terhadap masyarakat untuk melestarikan, menyayangi dan memberi penghidupan yang layak terhadap semua satwa.

Di Tanggerang terdapat organisasi yang menolong hewan tidak bermajikan atau liar dan penampungan hewan tersebut yang sudah cukup terkenal di Indonesia yaitu Animal Defender. Organisasi pecinta hewan ini berdiri sejak 2011. Masyarakat juga dapat berkontribusi dengan cara memberi donasi untuk membantu organisasi tersebut untuk terus menolong binatang. Banyak program yang dilakukan Animal Defender ini, melainkan Donate, Rescue, Rehabilitation, Education, Re-home, Visit Shelter dan Sponsor Steril. Salah satu organisasi tersebut adalah mengenai Adopt, Don't Shop! yang memberitahukan masyarakat untuk tidak membeli hewan peliharaan.

Menurut Ngalimun $(2017 ; 20)$ Komunikasi adalah proses pengiriman atau penyampaian berita atau informasi dari satu pihak kepihak lain dalam usaha untuk mendapatkan saling pengertian.

Agar hal tersebut dapat berjalan dengan baik juga, maka setiap organisasi memerlukan sebuah sarana atau media untuk mengkomunikasikan hal tersebut kepada khayalak luas. Salah satu sarana yang digunakan di organisasi Animal Defender yaitu event karena dapat digunakan juga untuk berbagi informasi, berkampanye, dan mengedukasi khalayak. Menurut Collin \& Ivanovic (2004), pameran adalah suatu kegiatan untuk menampilkan produk sehingga pembeli dapat melihatnya dan memutuskan untuk membelinya. Pameran merupakan event masyarakat yang diselenggarakan oleh suatu organisasi independen dan terbuka untuk umum. Pameran sengaja dirancang agar dapat diketahui oleh masyarakat luas seperti penyelenggaraan pameran tahunan ideal home atau untuk kalangan tertentu, 
misalnya pameran yang diperuntukkan bagi para pengusaha dan pengguna mesin packaging. (Lidia Evelina, 2007: p4). Pameran secara umum bisa dimanfaatkan untuk mendemonstrasikan dan menjelaskan sejarah atau suatu kebijakan perusahaan, bidang- bidang yang digeluti, dan tata cara pelaksanaannya. Melalui pameran dapat pula diceritakan secara lugas proses manufaktur, skala, operasional perusahaan, atau kampanye periklanan yang hendak dilancarkan dalam waktu dekat.

Dalam kasus peduli terhadap kesejahteraan hidup hewan, Animal Defender juga aktif melakukan event dan hasilnya dapat dilihat di website dan media sosial Animal Defender (Instagram, Youtube).

Peneliti memilih untuk membahas tentang organisasi Animal Defender ini karena ada suatu hal menarik dalam penelitian ini yaitu biasanya acara event di pusat perbelanjaaan atau mall bertujuan untuk memperkenalkan produk dan jasa. Akan tetapi, organisasi ini mengadakan acara event di mall untuk menggugah pecinta hewan baikpun orang yang tidak mencintai hewan untuk menyayangi hewan. Selain itu saat organisasi tersebut melaksanakan suatu event, banyak sekali masyarakat yang tertarik untuk mengadopsi dan tersadar untuk menyayangi binatang dikarena event tersebut.

Berdasarkan latar belakang tersebut rumusan masalah utama dalam penelitian ini adalah bagaimana proses komunikasi melalui kegiatan event adopt don't shop guna mengkampanyekan kesadaran masyarakat agar menyayangi binatang?. Tujuan penulis melakukan penelitian mengenai proses komunikasi melalui kegiatan event adopt don't shop guna menyadarkan masyarakat untuk menyayangi binatang karena ingin mengetahui bentuk proses komunikasi yang terjadi dalam event tersebut. Penulis memilih menggunakan proses komunikasi menurut Harold Laswell.

\section{Metode Penelitian}

Dalam penelitian ini penulis menggunakan metode penelitian deskriptif dengan pendekatan kualitatif. Menurut Penelitian kualitatif menurut Lexy J. Moleong dalam buku Metodologi Penelitian Kualitatif adalah penelitian yang bermaksud untuk memahami fenomena tentang apa yang dialami oleh subjek penelitian misalnya pelaku, persepsi, motivasi, tindakan dan lainnya secara holistik dengan cara deskripsi dalam bentuk kata-kata dan bahasa pada suatu konteks khusus yang alamiah dengan memanfaatkan berbagai metode alamia (Meleong, 2013:6). Sementara menurut Metode penelitian kualitatif menurut Vardiansyah adalah suatu penelitian yang menghindari perhitungan matematis dan data terukur, yang dicari adalah value atau nilai yang muncul dari objek kajian yang bersifat khusus; bahkan sangat spesifik, unik, mengandung tindakan bermakna, dan karenanya lebih menggunakan logika bahasa sebagai sarana berpikir ilmiah (Vardiansyah, 2005: 64).

Subjek penelitian penulis adalah perubahan kesadaran masyarakat untuk menyayangi hewan yang dilakukan Animal Defenders memalui event sedangkan objek penelitian adalah kegiatan event yang bertema adopt don't shop. Data yang diperlukan penulis diperoleh berdasarkan metode pengumpulan data melalui observasi, wawancara, dokumentasi dan studi pustaka. Tiga narasumber yang diwawancarai oleh penulis yakni Doni Herdaru Tona selaku CEO Yayasan Animal Defemders Indonesia, Walder selaku ketua Jakarta Dog Lovers, dan Kenjie Alexander selaku masyarakat yang pernah mengadopsi hewan.

Untuk membuktikan keabsahan data dari penelitian ini, penulis menggunakan teknik pemeriksaan keabsahan data dengan teknik triangulasi. Menurut Patton (dalam Sutopo, 2002:78) menyatakan bahwa ada empat macam teknik trianggulasi, 
yakni trianggulasi sumber, trianggulasi peneliti, trianggulasi metodologi, trianggulasi teoritis. Teori-teori tersebut akan mempermudah dalam memahami permasalahan yang dikaji dalam penelitian.

\section{Hasil Temuan dan Diskusi}

Dari hasil penelitian yang dilakukan penulis ditemukan:

a. Komunikasi Publik

"kalau event besar di area publik misalnya mall"." (wawancara dengan Doni Herdaru Tona di Shelter daerah Joglo, Jakarta Barat pada tanggal 3 Oktober 2018 pukul $13.30 \mathrm{WIB}$ ). Hasil dari wawancara penulis dengan narasumber mempunyai kesamaan dengan komunikasi public dimana komunikasi yang dilakukan di tempat yang ramai, atau tempat yang publik/ umum. Kedua, komunikasi publik merupakan sebuah kesempatan untuk mengungkapkan masalah sosial. Hal tersebut sesuai yang dilakukan oleh yayasan Animal Defenders Indonesia yaitu melakukan kegiatan event di mall dan kegiatan event tersebut mengkampanyekan kegiatan adopt don't shop yang merupakan masalah sosial.

b. Komunikasi Sosial

"yang mau kita ajarkan bahwa kalau ada yang salah, kalau ada yang aniaya, kalau ada penelantaran kita harus bergerak jangan pada diem doang. Trus ketika masyarakat bilang ngapain saya kita repot-tepot adopsi anjing kampong kayak gini. $\mathrm{Bu}$ ini jalan dia ketika dia rescue, ini fotonya, ini videonya ketika dia di operasi, ini masa penyembuhannya, ini setelah beresnya". "Orang-orang ketika kita jelaskan dengan baik, pelan-pelan, apa yaa, proper eksplaination akan lebih masuk disbanding kita membuat propaganda-propaganda berupa poster penganiayaan dan lain-lain yang fotonya groos banget dan lain-lain, yang fotonya disturbing gitu ya, orang gak tersentuh tapi cuman jijik doing, tapi kalau kita kasih liat kayak apa ini, kakinya patah, musti dipasangin pen, jalannya pincang". "Kita bicaranya kalian bisa apa sekarang, kalian bisa adopsi ya adopsi, kalian gak bisa adopsi ya poster, kalo gak ya donasi,kalo gak bisa donasi ya edukasi, kalo gak bisa edukasi ya volunteer. Ada banyak hal yang kita bisa terapkan, hal tersebut kita gak bisa terapkan di masyarakat umum, dia binggung. Ngapain nih gw donasi buat itu, ngapain gw tiba- tiba adopsi, buat cape. Jadi pendekatannya beda." (wawancara dengan Doni Herdaru Tona di Shelter daerah Joglo, Jakarta Barat pada tanggal 3 Oktober 2018 pukul 13.30 WIB)

Robinson (1992) dalam Kurniawati, Social marketing memang bukan sekadar memasarkan sebuah gagasan untuk tujuan non-profit. Sosial marketing atau pemasaran sosial pada intinya adalah upaya mengubah pandangan dan perilaku masyarakat melalui perubahan sosial. Cara yang dipandang paling tepat untuk melakukannya menurut Les adalah melalui pendidikan (2016:934). Berdasarkan hasil wawancara yang dikaitkan dengan teori komunikasi sosial dapat ditemukan bahwa sebuah sebuah perusahaan non-profit bukan hanya sekedar memasarkan sebuah gagasan tetapi untuk mengubah cara pandang dan perilaku manusia melalui perubahan sosial. Hal tersebut sesuai dengan yang dilakukan oleh yayasan Animal Defenders Indonesia yaitu menggunakan memberi contoh perubahan sosial agar masyarakat dapat merubah cara pandangnya terhadap hewan.

c. Komunikasi Massa

"Kita punya media sosial kita ada Instagram, facebook dan kalau group chat kita pake telegram messangers jadi untuk keseharian kita gunakan telegram messangers.". Walder menambahkan "Biasanya awalnya kita posting di Instagram, 
trus ke patch, trus kita forward ke group Facebook, trus kita copy juga buat internal. Kita posting juga di group telegram messengers." (wawancara dengan Walder di Taman Kodok Menteng Jakarta pada tanggal 13 Oktober 2018 pada pukul 16.00 WIB).

"Yaaa. Event ini kami selengarakan maupun kami diundang untuk mengisi di event tersebut, biasanya kami mengkampanyekan adopt don't buy, adopt don't shop gitu, ayok adopsi anjing dari shelter, melalui sosial media kita maupun website.". (wawancara dengan Doni Herdaru Tona di Shelter daerah Joglo, Jakarta Barat pada tanggal 3 Oktober 2018 pukul 13.30 WIB).

Teori komunikasi massa yaitu proses penggunaan sebuah media massa untuk mengirimkan pesan kepada audien yang luas untuk tujuan memberi informasi, menghibur, atau membujuk (Vivian, 2008: 450) dan dapat ditemukan dalam penelitian ini bahwa sebuah media massa digunakan untuk menyampaikan informasi. Hal tersebut sesuai dengan yang dipakai yayasan Animal Defenders Indonesia yaitu menggunakan youtube untuk mengedukasi atau memberi informasi mengenai bagaimana cara merawat dan bagaimana proses menyembuhkan penyakit pada hewan kesayangan.

d. Proses komunikasi

"Yang terlibat langsung paling pertama, baris depan adalah para pengurus, saya sendiri, pengurus harian gitu ya, lalu volunteer yang kami persilahkan berdasarkan keahlian". Kemudian penulis bertanya kepada narasumber ": Kalau gitu volunteer juga bisa membantu menyebarkan ke masyarakat luar juga yaa". Narasumber menjawab "Ya betul".

"Jadi pola komunikasi yang kita lakukan untuk mempromosikan event itu tersendiri, kami kaitan dengan kampanye yang akan kami lakukan, biasanya pada event steril dan vaksin kita akan bicara tentang kegunaan vaksin itu sendiri, setelah keuntungan dari steril. Tetapi ketika bicara tentang adopt don't buy, banyak nih anjing yang udah sehat nih, yang siap adopsi, kita bawa, kita bicara bukan mengenai keuntungan steril, tetapi keuntungan dari anjing yang sudah stabil kalau ambil dari shelter." (wawancara dengan Doni Herdaru Tona di Shelter daerah Joglo, Jakarta Barat pada tanggal 3 Oktober 2018 pukul $13.30 \mathrm{WIB}$ ).

Berdasarkan hasil wawancara yang dikaitkan dengan Teori dan Praktek, Effendy (2006: 11) mengatakan bahwa proses komunikasi pada hakikatnya adalah proses penyampaian pikiran atau perasaan oleh seseorang (komunikator) kepada orang lain (komunikan). Pikiran bisa merupakan gagasan, informasi, opini, dan lain-lain yang muncul dari benaknya. proses komunikasi dapat ditemukan bahwa terdapat lima pertanyaan yang perlu dijawab dalam proses komunikasi, yaitu who (siapa), says what (mengatakan apa), to whom (kepada siapa), in which channel (dalam media apa), with what effect (apa efeknya) sesuai dengan model komunikasi Laswell. Hal tersebut sesuai dengan yang dilakukan oleh yayasan Animal Defenders Indonesia yaitu who adalah Doni Herdaru dan para vollunter, says what adalah cara untuk meyayangi binatang, menjaga serta merawat, to whom adalah masyarakat yang bukan pecinta hewan, in which channel adalah kegiatan event, with what effect adalah menyadarkan masyarakat untuk menyayangi binatang.

\section{e. Event Pameran}

"Kami menggundang kawan-kawan datang ke seminar, kita bikin seminar, kita ikut seminar tentang bahaya daging anjing, bahaya rabies, pentingnya steril gitu ya, trus bikin workshop. Workshop tentang bagaimana menjadi owner yang baik. Bagaimana menanggani permasalahan perilaku anjing. misalnya anjingnya galak, 
gak bisa sosialisasi, anjingnya defensive, anjingnya rusakin barang ketika ditinggal, anjingnya ngejer-ngejer orang yang gak dikenal, anjingnya menggigit seisi keluarga, itu kita bikin workshopnya. Tujuannya adalah pada pola komunikasi ini apa yang saya punya bisa ditransformasikan kepada orang lain, bisa ditransfer ke orang lain sehingga orang lain punya ilmunya." (wawancara dengan Doni Herdaru Tona di Shelter daerah Joglo, Jakarta Barat pada tanggal 3 Oktober 2018 pukul 13.30 WIB).

Pameran merupakan event masyarakat yang diselenggarakan oleh suatu organisasi independent dan terbuka untuk umum. Pameran sengaja dirancang agar dapat diketahui oleh masyarakat luas seperti penyelenggaraan pameran tahunan ideal home atau untuk kalangan tertentu, misalnya pameran yang diperuntukkan bagi para pengusaha dan pengguna mesin packaging. (Lidia Evelina, 2007: p4). Dari pernyataan di atas dapat dilihat bahwa antara narasumber dengan teori tersebut sependapat, dilhat dari pernyataan narasumber saat diwawancarai yang mengatakan bahwa pameran adalah sebuah event untuk menyadarkan masyarakat mengenai keberadaan suatu organisasi.

f. Kampanye Komunikasi

“Biasanya kami mengkampanyekan adopt don't buy, adopt don't shop gitu, ayok adopsi anjing dari shelter, melalui sosial media kita maupun website. Yang perlu kita digaris bawahi adalah bukan sekedar orang-orang datang dan mengadopsi, tetapi bagaimana kita siap untuk berkomitmen ketika memelihara hewan, ketika kita tidak mempunyai komitmen maka penelantaran dan kasus kasus penganiayaan akan terus terjadi. Jadi pola komunikasi yang kita lakukan untuk mempromosikan event itu tersendiri, kami kaitkan dengan kampanye yang akan kami lakukan, biasanya pada event steril dan vaksin kita akan bicara tentang kegunaan vaksin itu sendiri, setelah keuntungan dari steril. Tetapi ketika bicara tentang adopt don't buy, banyak nih anjing yang udah sehat nih, yang siap adopsi, kita bawa, kita bicara bukan mengenai keuntungan steril, tetapi keuntungan dari anjing yang sudah stabil kalau ambil dari shelter" (wawancara dengan Doni Herdaru Tona di Shelter daerah Joglo, Jakarta Barat pada tanggal 3 Oktober 2018 pukul 13.30 WIB).

"Dari mulai belum punya anjing pun dengan edukasi mereka jadi bisa lebih pikir dua kali untuk memelihara anjing karena orang punya ajaran sebelum pelihara anjing, trus ikut sini dia jadi tau keperluannya banyak, umurnya panjang, jadi intinya komitmen sih yang kita edukasi kan disini." (wawancara dengan Walder di Taman Kodok Menteng Jakarta pada tanggal 13 Oktober 2018 pada pukul 16.00 WIB).

Dapat dilihat bahwa pernyataan key informan Doni sepedapat dengan teori yang dikatakan Muyasaroh tersebut dimana kampanye adalah bentuk tindakan komunikasi yang bertujuan mengubah pola pikir, perilaku termasuk di dalamnya adalah membangun kesadaran itu sendiri. Masing-masing organisasi penyelenggara kampaye, baik pemerintah, perusahaan swasta, lembaga swadaya masyarakat maupun lembaga lainnya mempunyai tujuan yang berbeda-beda (Muyasaroh, 2013: 18). Salah satu metode yang digunakan Yayasan Animal Defenders Indonesia untuk mengubah pola pikir masyarakat dan membangun kesadaran masyarakat itu sendiri. Selain itu setiap kampanye perubahan sosial yang dijalankan oleh Yayasan Animal Defenders Indonesia juga tidak terlepas dari aspek pengetahuan yaitu cara merawat hewan, sikap dan perilaku masyarakat terhadap hewan yang terlantar maupun yang dipelihara.

\section{g. New Media}

"Kita punya media sosial kita ada Instagram, facebook dan kalau group chat kita pake telegram messangers jadi untuk keseharian kita gunakan telegram messangers" 
(wawancara dengan Walder di Taman Kodok Menteng Jakarta pada tanggal 13 Oktober 2018 pada pukul $16.00 \mathrm{WIB}$ ).

Penulis mengaitkan pernyataan dari informan Walder dengan teori yang di kemukakan oleh Ardianto bahwa media baru juga tidak bisa dilepaskan dari indikasi mobilitas dalam penggunaan serta tidak terkendala oleh lokasi saat penerima maupun pengirim pesan (Ardianto, 2011:41), bahwa media baru tidak terkendala oleh waktu, lokasi saat penerima maupun pengirim pesan, dapat dilihat dari pernyataan informan Walder yang menyatakan bahwa komunikasi mereka selain bertemu langsung, melainkan mereka dapat berkomunikasi melalui media sosial tanpa terkendala oleh lokasi.

\section{h. Special Event}

"Sebetulnya lebih bagus langsung yah karena kan kita bisa langsung merasakan dan juga ngelihat gitu sih, jadi kayak kalau dari sosial media sosial kan cuman dibaca aja gitu, sekedar lewat juga nanti udahan bentaran juga lupa." (wawancara dengan Kenjie Alexander di Kantor Petra daerah Dadap pada tanggal 27 Oktober 2018 pada pukul 11.00 WIB)

Pernyataan dari informan Kenjie Alexander tersebut sependapat dengan key informan yang juga mengatakan hal yang sama bahwa kegiatan event sangat efektif untuk menyampaikan suatu produk maupun pesan kepada masyarakat. "Menurut saya komunikasi yang paling berhasil efeknya adalah ketika event dan bikin acara tanya jawab, talkshow." (wawancara dengan Doni Herdaru Tona di Shelter daerah Joglo, Jakarta Barat pada tanggal 3 Oktober 2018 pukul 13.30 WIB).

Teori yang dikatakan Yaverbaum dan dikutip oleh Wahyuni Pudjiastuti bahwa special event adalah media publisitas yang efektif karena dapat membantu dalam memasarkan perusahaan dan produk jasa kepada publik, sangat bersifat promosi, serta mampu mendapatkan publisitas banyak dari pihak media massa (Wahyuni Pudjiastuti.2010:17). Hal tersebut sesuai dengan penelitian ini yaitu kegiatan event merupakan media paling efektif seperti yang dikatakan Doni Herdaru dari Yayasan Animal Defenders Indonesia dan Kenjie Alexander yang merupakan masyarakat yang pernah mengadopsi anjing dikarenakan pernah mengikuti kegiatan event yang mengkampanyekan kegiatan adopt don't shop. Selain itu kegiatan event tersebut juga mendapat sorotan dari berbagai media massa salah satunya Metrotv News.

\section{Simpulan}

Dari penelitian ini diketahui bahwa dalam proses komunikasi yang terjadi pada Animal Defenders Indonesia komunikatornya adalah Doni Herdaru, pengurus, para volunteer dan tidak menutup kemungkinan masyarakat yang mengetahui pesan tersebut turut menjadi komunikator dengan menyebarkan pesan pada orang disekitarnya. Pesan yang disampaikan adalah tentang kampanye Adopt Don't Shop, mampu menumbuhkan kesadaran masyarakat untuk turut memperbaiki kehidupan hewan agar hidup layak dan tingkat penganiayaan dan penelantaraan hewan di kalangan masyarakat dapat berkurang. Media yang digunakan dalam menyampaikan pesan yaitu melalui media sosial Facebook, Twitter, Website, Youtube, Telegram dan Instagram serta event-event yang diselenggarakan. Sasaran dari kampanye yang dilakukan Animal Defenders Indonesia adalah masyarakat yang bukan pecinta hewan. Masyarakat menilai kegiatan yang dilakukan oleh Animal Defenders Indonesia adalah kegiatan yang positif dan menambah pengetahuan dan kegiatan yang dilakukan Animal Defenders Indonesia memiliki pengaruh untuk menyadarkan 
masyarakat agar memiliki respect terhadap hewan. Sebagai sebuah proses komunikasi, kampanye yang dilakukan oleh Animal Defenders Indonesia memberikan efek positif terhadap masyarakat. Masyarakat memberikan feedback yang positif terhadap pesan yang disampaikan oleh Animal Defenders Indonesia, yaitu memberikan donasi, muncul keinginan untuk mengadopsi hingga menjadi volunteer bagi Animal Defenders Indonesia.

Kegiatan event merupakan media yang paling efektif dan baik dalam menyampaikan suatu pesan penting kepada masyarakat secara luas karena dapat langsung memberikan contoh nyata kepada khalayak. Diera sekarang ini media merupakan salah satu hal terpenting untuk kehidupan saat ini, dikarenakan dengan media, proses menyampaikan pesan dapat secara tepat tanpa ada kendala lokasi maupun biaya.nilai dan sejarah.

\section{Ucapan Terima Kasih}

Penulis mengucapkan terima kasih kepada Suherman Kusniadji Drs., MM,M.I.Kom selaku Dosen Pembimbing, kedua orang tua dan adik penulis, key informan dan informan yang telah bersedia meluangkan waktunya serta semua pihak yang telah memberikan dukungan dan bantuan kepada penulis selama proses penyusunan jurnal penelitian ini.

\section{Daftar Pustaka}

Collin, P. H., \& Ivanovic, A. (2004). Dictionary of marketing (3rd ed.). USA: Bloomsbury Publishing.

Effendy, Onong Uchjana. (2006). Ilmu Komunikasi: Teori dan praktek. Bandung: PT. Remaja Rosdakarya.

Evelina, Lidia. (2007). Event Organizer Pameran. Jakarta: PT Indeks.

H.B. Sutopo. (2002). Pengantar Penelitian Kualitatif. Surakarta: Universitas Sebelas Maret Press.

Muyasaroh, S. (2013). Kampanye Perubahan Sosial (Kesadaran Masyarakat, Aspek Perubahan Kognitif dan Prilaku). Jurnal, Volume. 2 No. 1 Universitas Yudharta Pasuruan.

Moleong, Lexy J. (2013). Metodologi Penelitian Kualitatif. Bandung:Rosdakarya Mulyana.

Ngalimun. (2017). Ilmu Komunikasi: Sebuah Pengantar Praktis. Yogyakarta:Pustaka Baru Press.

Prosiding ICCIC: Komunikasi Insdustri \& Komunitas, cetakan ke 1, Jakarta, Fikom Untar 2016 ix-385 hlm, ISBN 978-602-74139-1-7. Penerbit Fikom Untar.

Pudjiastuti, Wahyuni. (2010). Special Event. Jakarta: PT. Elex Media Komputindo.

Vardiansyah, Dani. (2005). Filsafat Ilmu Komunikasi (Suatu Pengantar). Jakarta: PT Indeks Kelompok Gramedia.

Vivian, John. (2008). Teori Komunikasi Massa. Edisi 8. Jakarta: Kencana 